\title{
Laparoscopy, dorsal lumbotomy and flank incision live donor nephrectomy: comparison of donor outcomes
}

\author{
Dinesh Samarasekera, MD;* David S.H. Kim, MD; ${ }^{\dagger}$ Rachel Wang; Gordon Yip, MD; Steven S. Tang, MD;* \\ Christopher Nguan, MD, FRCSC*
}

*Department of Urologic Sciences, University of British Columbia, Vancouver, BC; †University of British Columbia, Vancouver, BC

Cite as: Can Urol Assoc J 2013;7:E69-E73. http://dx.doi.org/10.5489/cuai.266. Epub 2011 July 4.

\section{Abstract}

Background: Flank incision (FL), dorsal lumbotomy (DL) and laparoscopic surgery have been effective approaches to donor nephrectomy. While laparoscopic donor nephrectomy (LDN) has become increasingly popular, there has yet to be a direct comparison of the three modalities.

Methods: We performed a retrospective chart review of FL, DL and LDN operations between 2002 and 2010 within a single institution. Donor and recipient characteristics, as well as surgical outcomes, were assessed.

Results: There were 496 donor nephrectomy operations available for analyses. Patients in the LDN group had the lowest estimated blood loss, compared to the DL and FL groups ( $p<0.001)$, lowest rate of complications $(p<0.01)$, and shortest hospital stay $(p<0.0001)$. Donors who underwent DL used an average of $60.12 \pm 5.0 \mathrm{mg}$ of morphine, which was significantly less than that used by patients in the LDN $(93.2 \mathrm{mg}, p<0.0001)$ and FL $(111.82 \mathrm{mg}, p<0.001)$ groups. Mean serum creatinine of recipients at day 1 post-op was the highest in the FL group $(p<0.0001$ FL vs. LDN, $p<0.001 \mathrm{FL}$ vs. DL), but there were no significant differences between the three groups at 2 weeks, $6,12,18$, and 24 months post-operation $(p>0.45)$.

Conclusions: Although a lower pain experience of LDN was not indicated, the use of LDN should be favoured over DL and FL as it is associated with fewer complications, and shorter length of stay. Of note, DL appears to be associated with higher complications and is likely not a preferred option for donor nephrectomy.

\section{Résumé}

Contexte : L'incision du flanc, la lombotomie dorsale et la laparoscopie sont des techniques efficaces pour une néphrectomie chez un donneur vivant. Même si la laparoscopie a connu une montée en popularité, aucune comparaison directe entre les trois modalités n'a été effectuée.

Méthodologie : Nous avons procédé à un examen rétrospectif des dossiers de patients ayant subi une néphrectomie par incision du flanc, par lombotomie dorsale et par laparoscopie entre 2002 et 2010 dans un même établissement. Les caractéristiques des donneurs et des receveurs ainsi que les résultats de la chirurgie ont été évalués. Résultats : Les analyses ont porté sur 496 néphrectomies. En comparaison avec les donneurs ayant subi une incision du flanc ou une lombotomie dorsale, les donneurs ayant subi une laparoscopie présentaient la perte sanguine estimée la plus faible $(p<0,001)$, le taux le plus bas de complications $(p<0,01)$ et la plus courte durée du séjour en hôpital ( $p<0,0001)$. Les donneurs qui ont subi une lombotomie dorsale ont utilisé en moyenne 60,12 \pm 5,0 mg de morphine, soit une valeur significativement plus faible que celle notée chez les patients ayant subi une laparoscopie $(93,2 \mathrm{mg}, p<$ $0,0001)$ et une incision du flanc $(111,82 \mathrm{mg}, p<0,001)$. Le taux moyen de créatinine sérique le lendemain de l'intervention était le plus élevé chez les patients ayant subi une incision du flanc ( $p<0,0001$ incision du flanc vs laparoscopie, $p<0,001$ incision du flanc vs lombotomie dorsale), mais les différences entre les trois groupes n'étaient pas significatives 2 semaines, 6, 12, 18 et 24 mois après l'opération $(p>0,45)$.

Conclusions : Même si aucune réduction de la douleur n'a été observée avec la laparoscopie, il faut tout de même favoriser le recours à cette technique plutôt qu'à une lombotomie dorsale ou une incision du flanc, car elle est associée à moins de complications et à un séjour plus court en hôpital. Il est à noter que la lombotomie dorsale semble associée à un taux plus élevé de complications et n'est probablement pas une option à privilégier pour une néphrectomie chez un donneur.

\section{Introduction}

The first open donor nephrectomy (ODN) was performed in 1954; ${ }^{1}$ for 45 years, it remained the gold standard. The retroperitoneal flank approach provides good access to the vessels of the renal hilum and avoids disturbance to intraabdominal viscera. The main disadvantages of the flank incision are increased postoperative pain and prolonged recovery consequent to the incision of multiple muscle layers. ${ }^{2}$ Another approach that has been previously advocated for radical nephrectomy, renal stone and pyeloplasty procedures is the dorsal lumbotomy (DL). ${ }^{3}$ It has a key advantage over the standard flank incision (FL) in that no muscles are transected, rather a muscle-splitting approach is used. ${ }^{3}$ As a result, DL closures are quicker, stronger and result in less postoperative morbidity. ${ }^{3}$ However, the posterior approach 
of DL provides poor hilar visualization and can potentially increase the risk of intraoperative hemorrhage. Additionally, for high-lying or enlarged kidneys, DL incisions may not provide adequate exposure and risk poor control of the hilum.

In 1995, the first laparoscopic living donor nephrectomy (LDN) was performed; 4 since then, the technique has become increasingly popular due to its documented safety profile and reduced postoperative morbidity. Specific benefits include decreased postoperative recovery time, a faster return to full activity, improved cosmesis and less postoperative pain. ${ }^{5,6}$ More recent studies have shown that the short-term outcomes of allograft performance following LDN are equivalent to the open flank procedure..$^{7-9}$ However, Nogueira and colleagues ${ }^{10}$ and Ratners and colleagues ${ }^{11}$ found lower mean serum creatinine levels at 1 year post-transplant after LDN compared to open flank renal procurement. In their series, LDN donor kidneys were slower to achieve a nadir serum creatinine, but this had no effect on long-term outcomes. There was also no significant difference in complication rates between the LDN and ODN groups.

As there is yet to be any direct comparison between flank, DL and laparoscopic approaches, specifically for donor nephrectomy in the literature, we present our single institution experience with these three procedures.

\section{Patients and methods}

A retrospective review of patients undergoing laparoscopic, flank-incision, and dorsal lumbotomy donor nephrectomy operations between 2002 and 2010 at the Vancouver General Hospital (Vancouver, BC, Canada) renal transplant program was conducted. The procedures were carried out by surgeons who are experts in their respective procedures, and a single surgeon performed the open operations, and a second laparoscopic-trained surgeon performed the LDN procedures. The donor parameters evaluated included donor age, operative side, preoperative serum creatinine, postoperative serum creatinine, estimated blood loss, operative time, intraoperative complications, postoperative complications, equivalent analgesia use and length of stay in hospital. Postoperative analgesia included on-demand parenteral narcotics, such as patient controlled analgesia (PCA), and oral narcotics used during the course of the donors' stay in hospital. Most patients received ketorolac infusion in the initial 24 hours post-operation, and in some cases, postoperative fentanyl or morphine epidural analgesia was prescribed by the hospital Acute Pain Service. All opioid narcotics were converted to equivalent parenteral morphine amounts, but ketorolac and epidural analgesia were not factored into our equivalent analgesia calculation. Recipient outcomes were evaluated, including short- and long-term renal function, graft rejection and frequency of delayed graft function. Pediatric recipients and their corresponding donors were excluded.

\begin{tabular}{|c|c|c|c|}
\hline & $\begin{array}{c}\text { LDN } \\
\text { (n= 242) }\end{array}$ & $\begin{array}{c}D L \\
(n=116)\end{array}$ & $\begin{array}{c}\text { FL } \\
(n=138)\end{array}$ \\
\hline $\begin{array}{l}\text { Donor age } \\
\text { (years) }\end{array}$ & $46.79 \pm 0.76$ & $44.26 \pm 0.99$ & $41.92 \pm 0.83$ \\
\hline $\begin{array}{l}\text { Donor } \\
\text { BMI }\end{array}$ & $25.59 \pm 0.38$ & $25.36 \pm 0.47$ & $24.84 \pm 0.32$ \\
\hline $\begin{array}{l}\text { Donor operative } \\
\text { side }(L / R)\end{array}$ & $240 / 2$ & $88 / 27$ & $91 / 47$ \\
\hline $\begin{array}{l}\text { Donor } \\
\text { preoperative } \\
\text { serum } \mathrm{Cr} \\
(\mu \mathrm{mol} / \mathrm{L})\end{array}$ & $74.19 \pm 1.29 *$ & $73.99 \pm 1.27 \dagger$ & $78.17 \pm 1.13$ \\
\hline $\begin{array}{l}\text { Recipient age } \\
\text { (years) }\end{array}$ & $48.19 \pm 1.10$ & $44.81 \pm 1.18$ & $43.88 \pm 1.04$ \\
\hline $\begin{array}{l}\text { Recipient } \\
\text { transplant \# }\end{array}$ & $1.08 \pm 0.04$ & $1.12 \pm 0.034$ & $1.11 \pm 0.029$ \\
\hline
\end{tabular}

LDN: laparoscopic donor nephrectomy; DL: dorsal lumbotomy; FL: flank incision ; BMI: body mass index. Values reported as mean $\pm \mathrm{SE} ;{ }^{*} p<0.01 \mathrm{LDN}$ vs. $\mathrm{FL} ; \dagger p<0.01 \mathrm{DL}$ vs. FL.

Statistical analysis was carried out using the Statview analysis software (SAS Institute Inc., Cary, NC). Student's t-test was used to compare continuous variables, and ChiSquare analysis was used to analyze categorical variables. Statistical significance was defined as $p<0.05$.

\section{Results}

A total of 496 donor nephrectomy patients were available for study (Table 1). Patient demographics were comparable across groups including donor age, body mass index and recipient characteristics (Table 1). Preoperative serum creatinine levels were significantly higher in patients in the $\mathrm{FL}$ group compared to both LDN and DL groups $(78.17 \mu \mathrm{mol} / \mathrm{L}$ vs. $74.19 \mu \mathrm{mol} / \mathrm{L}$ and $73.99 \mu \mathrm{mol} / \mathrm{L} ; p<0.01)$, but there was no significant difference between the LDN and DL groups. Ninety-nine percent (240 cases) of LDN, 67\% (91 cases) of $\mathrm{DL}$ and $76 \%$ (88 cases) of FL were performed on the left side.

Table 2. Donor outcomes

\section{LDN}

\begin{tabular}{|c|c|c|c|}
\hline $\begin{array}{l}\text { OR time } \\
\text { (min) }\end{array}$ & $199.29 \pm 4.01 *$ & $117.68 \pm 2.28^{*}$ & $181.6 \pm 3.12$ \\
\hline $\begin{array}{l}\text { Estimated blood } \\
\text { loss }(\mathrm{mL})\end{array}$ & $72.09 \pm 5.20^{* \dagger}$ & $278.02 \pm 20.66^{*}$ & $187.86 \pm 13.09$ \\
\hline $\begin{array}{l}\text { Morphine } \\
\text { equivalents (mg) }\end{array}$ & $93.23 \pm 5.57^{*}$ & $60.12 \pm 5.0^{*}$ & $111.82 \pm 11.97$ \\
\hline $\begin{array}{l}\text { Donor post- } \\
\text { operative day } \\
1 \mathrm{Cr}(\mu \mathrm{mol} / \mathrm{L})\end{array}$ & $111.62 \pm 1.89$ & $100.82 \pm 2.10^{¥}$ & $115.31 \pm 2.17$ \\
\hline $\begin{array}{l}\text { Length of stay } \\
\text { (days) }\end{array}$ & $3.71 \pm 0.19^{t^{* *}}$ & $4.08 \pm 0.13^{¥}$ & $4.60 \pm 0.08$ \\
\hline \multicolumn{4}{|c|}{$\begin{array}{l}\text { OR: operating room; LDN: laparoscopic donor nephrectomy; DL: dorsal lumbotomy; FL: flank } \\
\text { incision. } \\
\text { Values reported as mean } \pm \mathrm{SE} ;{ }^{*} p<0.0001 \mathrm{LDN} \text { vs. DL; } \dagger p<0.0001 \mathrm{LDN} \text { vs. FL; } ¥ p<0.001 \\
\text { DL vs. FL; }{ }^{* *} p<0.05 \mathrm{LDN} \text { vs. DL. }\end{array}$} \\
\hline
\end{tabular}




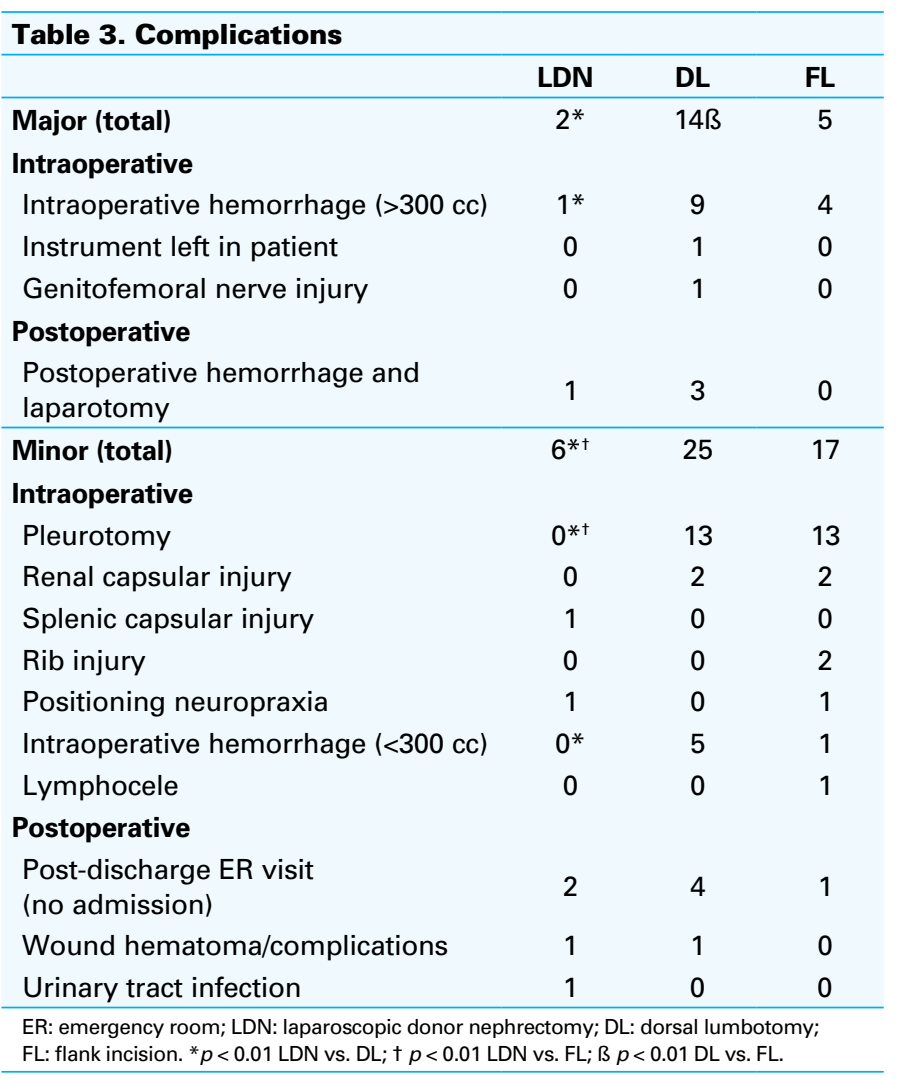

The LDN group observed significantly less intraoperative blood loss $(72.09 \mathrm{~mL})$ compared to the $\mathrm{DL}(278.02 \mathrm{~mL}$, $p<0.0001)$ and FL $(187.9 \mathrm{~mL}, p<0.0001)$ groups (Table $2)$. Intraoperative blood loss in FL patients was also significantly lower than that of DL patients $(p<0.0001)$. Operative time was significantly shorter with DL (117.68 min) compared to LDN (199.29 $\mathrm{min}, p<0.0001)$ and FL $(181.6 \mathrm{~min}$, $p<0.0001)$.

Major intraoperative and postoperative complications were more prevalent in the $D L$ group $(n=14)$ compared to $\operatorname{LDN}(\mathrm{n}=2, p<0.01)$ and FL $(\mathrm{n}=5, p<0.01)$ (Table 3$)$. A marked difference in the incidence of intraoperative hemorrhage $(>300 \mathrm{cc})$ was seen in the DL group $(\mathrm{n}=9)$ compared to the LDN $(\mathrm{n}=1 ; p<0.01)$ group. Additionally, 3 patients in the DL group and 1 patient in the LDN group required a return to the operating room (OR) for postoperative hemorrhage. The incidence of minor complications was higher in $\mathrm{DL}$ and FL patients ( $\mathrm{n}=25$ and $\mathrm{n}=17$, respectively) compared to LDN patients ( $\mathrm{n}=6 ; p<0.01$ ); however, no difference was observed between DL and FL patients $(p=0.154)$. The most common minor complication in both the $\mathrm{DL}$ and FL groups was pleurotomy ( $\mathrm{n}=13$ in both), which was repaired intraoperatively without requirement for chest tube drainage in all cases. There was also an increased incidence of minor intraoperative hemorrhage $(<300 \mathrm{cc})$ in the DL group compared to the LDN group ( 5 vs. 0 , respectively; $p<0.01)$.

\begin{tabular}{lccc}
\hline Table 4. Post-transplantation graft failures & & \\
\hline & LDN & DL & FL \\
\hline Early & 0 & 0 & 1 \\
Acute rejection & 0 & 1 & 0 \\
Acute tubular necrosis & 0 & 0 & 1 \\
Graft infection & 0 & 1 & 2 \\
Graft thrombosis & 0 & 1 & 0 \\
Vascular rejection & & & \\
Late & 0 & 0 & 1 \\
Unknown & 0 & 0 & 2 \\
Recurrent disease & 2 & 1 & 0 \\
Chronic allograft nephropathy & 2 & 4 & 7 \\
Total & & \\
\hline LDN: laparoscopic donor nephrectomy; DL: dorsal lumbotomy; FL: flank incision. &
\end{tabular}

There was no significant difference in short- and long-term graft function (Table 4). Specifically, there was no significant difference in calculated creatinine clearance between the LDN, DL, and FL groups at 1 week (Fig. 1) using CockroftGault $(53.19,52.00$, and $55.77 \mathrm{~mL} / \mathrm{min}$, respectively; $p$ $>0.18), 1$ month $(63.78,64.13$, and $62.93 \mathrm{~mL} / \mathrm{min}$, respectively; $p>0.62), 6$ months $(67.22,67.23$, and $65.70 \mathrm{~mL} /$ min, respectively; $p>0.56), 12$ months $(69.01,69.99$, and $67.29 \mathrm{~mL} / \mathrm{min}$, respectively; $p>0.33), 18$ months $(66.48$, 70.10 , and $70.48 \mathrm{~mL} / \mathrm{min}$, respectively; $p>0.38$ ) and at 24 months $(70.75,70.96,70.20$, respectively; $p>0.82)$. Graft failures were noted in all groups in both the short and long term (Table 4$)$, experienced most often by FL patients $(n=7)$, followed by DL $(n=4)$ and LDN $(n=2)$ patients. There was no significant difference between the rates of graft failure in the three groups.

\section{Discussion}

Since LDN entered the realm of transplantation in $1995,{ }^{4}$ it has been scrutinized because of its technically challenging nature, longer operating time, and associated longer warm ischemia time. ${ }^{6}$ It was hypothesized that these factors would lead to an increased rate of graft dysfunction and failure; however, the literature fails to corroborate this. ${ }^{10-12}$ Hazebroek and colleagues showed that pneumoperitoneum during LDN does not adversely affect the renal function of donors or recipients. ${ }^{7}$ London and colleagues reported that increased intraoperative fluid administration could overcome decreased renal blood flow during LDN and prevent renal ischemia. ${ }^{8}$ Goel and colleagues found that while early graft recovery may be slower in LDN allografts, long-term mean serum creatinine levels were lower in LDN patients compared to open donor nephrectomy patients. ${ }^{9}$ As a result of its equivalent safety profile, comparable graft outcomes and significant benefits to the donor, LDN has become a routine method for renal procurement in living kidney donor transplantation. Although techniques such as mini-FL have 


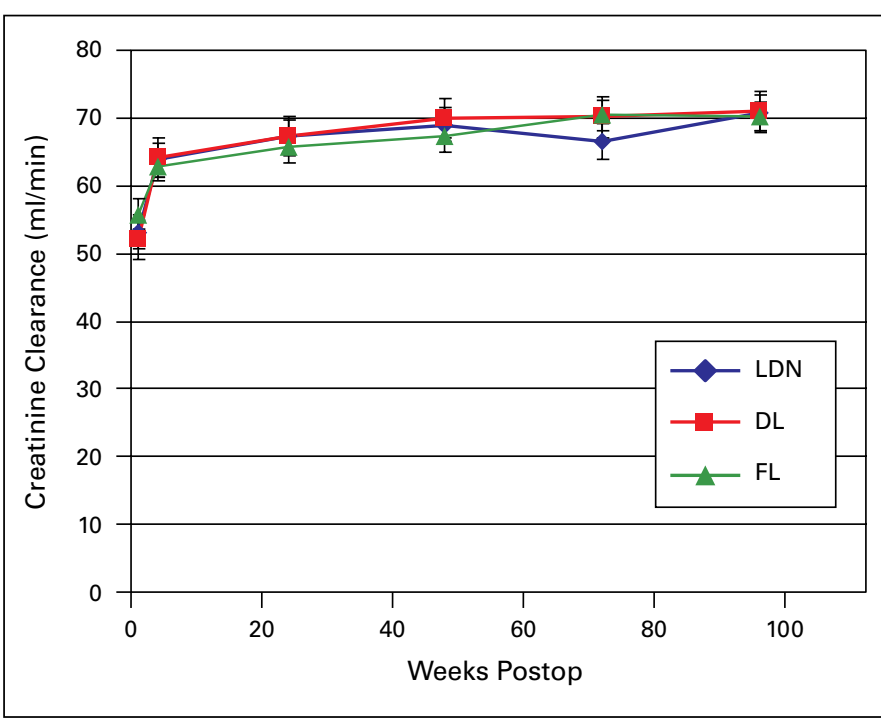

Fig. 1. Postoperative Cockcroft-Gault eGFR calculated creatinine clearance for donor procured allografts from laparoscopic (LDN), dorsal lumbotomy (DL) and standard flank incision (FL) procedures.

been promoted as alternatives to LDN, direct comparisons have shown that laparoscopic donors require less analgesia, and have shorter hospital stays and faster recovery to routine duties. ${ }^{12-14}$

The DL incision is seldomly used by contemporary North American surgeons for live donor nephrectomy due to its technically challenging nature and poor hilar visualization. As a result, there are no studies comparing LDN and DL, and few comparing DL and FL. Our centre has had the benefit of experience with all three techniques, and we present the results of the first single institution comparison amongst them.

Patients who underwent LDN experienced significantly lower intraoperative blood loss compared to both FL and DL procedures. The meticulous tissue dissection and presence of pneumoperitoneum during laparoscopic surgery was likely a contributing factor. With a DL approach, the spine of the kidney is addressed first, and then the surgeon must dissect medially along the renal sinus anterior and posterior to secure the hilum. This approach puts the kidney continually between the surgeon and the hilar insertion on the great vessels. As such, visualization of the hilar vessels is relatively poor and, as a consequence, bleeding can be encountered and difficult to control.

Hospital stays of LDN patients were significantly shorter than FL patients, which is consistent with data from other studies. $5,6,12,13$ Dorsal lumbotomy patients also had shorter hospital stays than FL patients, likely related to the application of muscle-splitting rather than a muscle-cutting approach.

Numerous studies have reported decreased use of narcotic analgesics following laparoscopic procedures. ${ }^{4-6,12-14}$ Morphine equivalents used in our LDN group were actually higher than that of our DL group and not different from that of the FL group. However, $62 \%(n=85)$ of our FL patients used adjuvant epidural analgesia, which was not included in our morphine equivalent measure of pain management. No patients in the laparoscopic group received epidural analgesia. As well, on demand parenteral narcotics were not routinely offered during the early periods of the study, which coincided with the early introduction of LDN. The proportion of surgical methods in this study progressed from low LDN and higher DL use to higher LDN and less DL use. This resulted in parenteral narcotics being routinely offered to a larger proportion of LDN patients compared to DL patients.

In our study, there were no significant differences in shortand long-term graft function among the LDN, DL and FL groups, despite the longer OR time in the LDN group. The rates and causes of graft failure were not significantly different among the LDN, DL and FL groups. Several studies comparing LDN to a standard FL and mini-FL have found similar results in living renal donor surgery. ${ }^{12-15}$

To our knowledge, this study represents one of the only studies that directly compare LDN with standard FL and DL approaches. Braga and colleagues examined open flank, DL and laparoscopic procedures to treat ureteropelvic junction obstruction; they also observed that the laparoscopic approach had the longest operative time, but the shortest hospital stay, which is similar to our results. ${ }^{3}$ With ongoing increased adoption of LDN, it is likely that LDN operative times will be reduced, and approach that of its open counterparts. ${ }^{3}$ Patients in the LDN group lost a significantly lower amount of blood intraoperatively, experienced a lower rate of major and minor complications and spent less time in hospital postoperatively than patients in either the FL or DL groups. Additionally, patients undergoing laparoscopic nephrectomy used less analgesia postoperatively than patients undergoing flank incisions. Analgesic use in DL patients appears lower than that of LDN patients, and this result may represent an underestimation of narcotic use in this population who received epidural anesthesia; however, these results may also allude to the efficacy of a muscle-splitting incision in reducing postoperative pain. Unfortunately, the significantly higher incidence of complications and blood loss in the DL group contributes to a poorer safety profile. These, combined with relatively poor operative characteristics, are significant limitations to the widespread adoption of DL as a renal procurement operation for transplantation. In many centres, DL approaches are commonly used for renal surgery, including pyeloplasty and stone surgery, for which this technique was initially developed. However, it appears that the need for maximal proximal vascular control in donor nephrectomy negates any advantages of incision location due to higher complication rates. 


\section{Conclusion}

Long-term graft performance was equivalent between LDN, FL and DL groups, suggesting that longer OR time incurred with LDN does not have a significant effect on eventual graft function. This lack of diminished graft performance, as well as the improved safety profile further supports LDN as an effective surgical procedure for donor nephrectomy. While the open FL remains the traditional fallback approach for donor nephrectomy, LDN is superior to both the FL and DL approaches, with respect to hospital stay and intraoperative and postoperative complications.

Competing interests: None declared.

This paper has been peer-reviewed.

\section{References}

1. Murray JE, Merrill JP, Harrison JH. Renal homotransplantation in identical twins. J Am Soc Nephrol 2001;12:201-4.

2. Onol FF, Akbas A, Kose 0 , et al. Short stay pyeloplasty with transverse dorsal lumbotomy incision: our 10-year experience. Urology 2009;74:1309-12.

3. Braga $L H$, Lorenzo AJ, Bagli DJ, et al. Comparison of flank, dorsal lumbotomy and laparoscopic approaches for dismembered pyeloplasty in children older than 3 years with ureteropelvic junction obstruction. J Urol 2010;183:306-11.
4. Ratner LE, Ciseck LJ, Moore RG, et al. Laparoscopic live donor nephrectomy. Transplantation 1995;60:1047-9.

5. Ratner LE, Kavoussi LR, Schulam PG, et al. Comparison of laparoscopic live donor nephrectomy versus the standard open approach. Transplant Proc 1997;29:138-9.

6. Flowers JL, Jacobs $\mathrm{S}$, Cho E, et al. Comparison of open and laparoscopic live donor nephrectomy. Ann Surg 1997;226:483-9; discussion 489-90.

7. Hazebroek EJ, de Bruin RW, Bouvy ND, et al. Long-term impact of pneumoperitoneum used for laparoscopic donor nephrectomy on renal function and histomorphology in donor and recipient rats. Ann Surg 2003:237:351-7.

8. London ET, Ho HS, Neuhaus AM, et al. Effect of intravascular volume expansion on renal function during prolonged C02 pneumoperitoneum. Ann Surg 2000;231:195-201.

9. Goel MC, Modlin CS, Mottoo AM, et al. Fate of donor kidney: laparoscopic versus open technique. J Urol 2004; 172:2326-30.

10. Nogueira JM, Cangro CB, Fink JC, et al. A comparison of recipient renal outcomes with laparoscopic versus open live donor nephrectomy. Transplantation 1999;67:722-8.

11. Ratner LE, Montgomery RA, Maley WR, et al. Laparoscopic live donor nephrectomy: the recipient. Transplantation 2000;69:2319-23.

12. Kok NF, Lind MY, Hansson BM, et al. Comparison of laparoscopic and mini incision open donor nephrectomy: single blind, randomized controlled clinical trial. BMJ 2006;333:221.

13. Kok NF, Alwayn IP, Lind MY, et al. Living donor nephrectomy: mini-incision muscle-splitting open approach versus laparoscopy. Transplantation 2006;72:881-7.

14. Perry KT, Freedland SJ, Hu JC, et al. Quality of life, pain, and return to normal activities following laparoscopic donor nephrectomy versus open mini-incision donor nephrectomy. J Urol 2003;169:2018-21.

15. Kwok NF, Alwayn IP, Tran, KT, et al. Psychosocial and physical impairment after mini-incision open and laparoscopic donor nephrectomy: a prospective study. Transplantation 2006;82:1291-7.

Correspondence: Dr. Christopher Nguan, 6th floor Urology, 2775 Laurel St, Vancouver, BC V5Z 1M9; fax: 604-875-5604; info@nguan.ca 